\title{
Tables and Figure
}

\section{TABLES}

1. Perceptions of Population Growth 35

2. NORC Respondents at Different Growth Rates 38

3. Accurate Perceptions of Population Growth 39

4. Central-City Residents and Population Change 42

5. Suburban Residents and Population Change 44

6. Central-City Survey Respondents at Different Growth Rates 65

7. Central-City Respondents' Evaluations of Local Services and Facilities 67

8. Residential Satisfaction of Central-City Respondents 69

9. Social Relationship and Personal Well-Being Reports of Central-City Respondents 71

10. Suburban Survey Respondents at Different Growth Rates 90

11. Suburban Respondents' Evaluations of Local Services and Facilities 92

12. Residential Satisfaction of Suburban Respondents 94

13. Social Relationship and Personal Well-Being Reports of Suburban Respondents 97

14. Nonmetropolitan Survey Respondents at Different Growth Rates 120

15. Nonmetropolitan Respondents' Evaluations of Local Services and Facilities 121

16. Residential Satisfaction of Nonmetropolitan Respondents 123

17. Social Relationship and Personal Well-Being Reports of Nonmetropolitan Respondents 126

\section{FIGURE}

1. Population Change for 5-year Periods 4 